\title{
Evaluating the case for supporting renewable electricity*
}

May 18, 2018

\begin{abstract}
Renewable electricity, particularly solar PV and wind, creates external benefits of learningby-doing that drive down costs and reduce $\mathrm{CO}_{2}$ emissions. The Global Apollo Programme called for collective action to develop renewable energy. This paper sets out a method for assessing whether a trajectory of investment that involves initial subsidies is justified by the subsequent learning-by-doing spillovers and if so, computes the maximum justifiable additional subsidy to provide, taking account of the special features of renewable electricity geographically dispersed and variable quality resource base and local saturation. Given current costs and learning rates, accelerating the current rate of investment appears globally socially beneficial for solar PV in most but not all cases, less so for on-shore wind. The optimal trajectory appears to involve a gradually decreasing rate of growth of installed capacity.
\end{abstract}

\section{The case for supporting renewables}

The Global Apollo Programme called for collective action with "one aim only - to develop renewable energy supplies that are cheaper than those from fossil fuels. ... These price trends help to create a prima facie case in favour of focussing heavily on solar energy." (King et al., 2015, p15). The case for support is primarily to compensate for the otherwise unremunerated learning spill-overs arising from cumulative production. Each additional installation adds to the cumulative production, which figure $1^{1}$ persuasively suggests is the prime driver of cost reductions

*This paper was prompted by Neuhoff (2008), who was pessimistic about the social profitability of PV when its cost was much higher, but noted that increasing current investment might relax constraints on future investment rates, which conferred an additional and potentially large extra benefit. I am indebted to insightful comments from Rutger-Jan Lange, and very careful checking of the paper and formulae to Linden Ralph and Bowei Guo, as well as to very helpful reviewers.

${ }^{1}$ Source: Delphi234 - Own work, CC0, https://commons.wikimedia.org/w/index.php?curid=33955173. The straight green line predicts that modules decrease in price by $20 \%$ for every doubling of cumulative shipped modules. The other line (with squares) shows world-wide module shipments vs. average module price. The data 
of solar modules (Fraunhofer, 2016; Rubin et al., 2015a). Renewable electricity technologies, particularly wind and solar PV (hereafter just PV), have been heavily subsidized for many years. Both PV and wind are finally at the point of becoming commercially viable without subsidies in some locations, but new installations continue to enjoy significant, if now much lower, support in many jurisdictions. This paper asks whether past and continued support for such technologies is justified, and, more fundamentally, how to determine the appropriate level of support now and in the future for emerging low-carbon technologies with learning spillovers. While it is easy to present qualitative arguments for such support, the practical question is to quantify the level of justified support, and relate it to observable features of the technology and the location. The strongest case is one in which all countries recognize the social value of supporting immature zero-carbon technologies and collectively fund that support. Mission Innovation is a recent example, through which "22 countries and the European Union are taking action to double their public clean energy R\&D investment over five years". ${ }^{2}$

This paper provides a method for calculating the justified subsidy to compensate for the learning spillovers. There is typically also a shortfall between the social cost of carbon and its market price to account for in the social cost-benefit analysis. To justify the learning subsidy the investment must be socially profitable - if it never becomes socially profitable there is little point in pursuing these cost reductions. The paper sets out a methodology for a social cost-benefit analysis of a global support programme for low-carbon electricity generation technologies, illustrated for PV and on-shore wind. The electricity supply industry has particular characteristics that need careful modeling if the results are to carry credibility. Consumption is constrained by current available capacity as storage is costly, and transmission constraints limit the size of the market that can be supplied from local capacity. As a result the value of electricity can vary strongly over time and space in ways that make the concept of a global market inappropriate. Local saturation is an important element, while the value of any one low-carbon option depends on what others are available and when they become competitive. A key issue is whether to accelerate deployment to reap earlier learning, or delay until the technology becomes more competitive against rising fossil energy costs. ${ }^{3}$

\footnotetext{
are from ITRPV 2015 edition and can be updated to 2015 with ITRPV (2016). later updates are available annually at http://www.itrpv.net/Reports/Downloads/.

${ }^{2}$ See http://mission-innovation.net/

${ }^{3}$ Grubb et al. (2002) review the implications of induced technical change for energy modeling. They note the contrast between learning, which argues for earlier support for climate mitigation, while autonomous technical change argues for later support when more knowledge has accumulated, making action later cheaper. Our emphasis is on changing relative costs rather than autonomous technical change.
} 


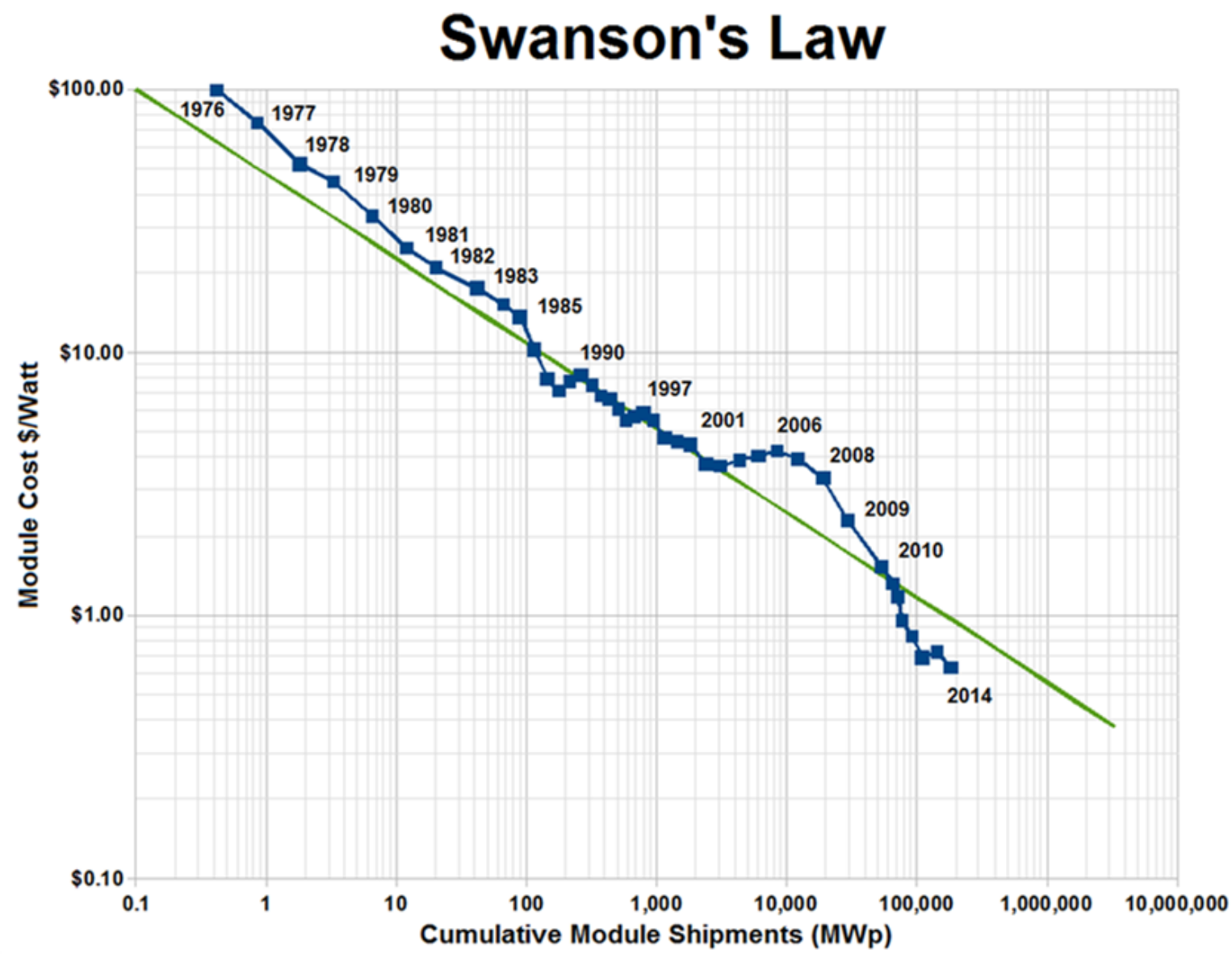

Figure 1: PV Module price reductions

\subsection{Literature review}

The idea of including learning-by-doing as a general driver of technical progress dates back at least to Arrow (1962), and has spawned an extensive literature. ${ }^{4}$ Two immediately relevant strands are the extent to which cost falls can be reliably estimated and attributed to cumulative deployment (Rubin et al., 2015a) or R\&D (Jamasb, 2007; Nordhaus, 2014), ${ }^{5}$ and the policy implications of the market failure of unremunerated spillovers. The focus here is on low-carbon technologies, which, because of heavy subsidies, have attracted particular attention. Most papers study how specific subsidy policies have worked and whether they were justified (e.g. Bollinger

${ }^{4}$ The concept has been influential in both policy design (e.g. Succar, 1978) oligopoly pricing policy (e.g. Spence, 1981), and industrial and trade strategy (e.g. Ghemawat and Spence, 1985; Dasgupta and Stiglitz 1988).

${ }^{5}$ Grubb et al. (2002) and Gambhir et al. (2014) note the complex interactions between R\&D and deployment, with increased deployment stimulating more R\&D and vice versa, supporting the view that increments in cumulative capacity are the main factor driving down costs in later near-market stages. Papineau (2006) cautions that adding time and $R \& D$ makes cumulative production statistically insignificant; a reflection of the often high colinearity between time and log cumulative output. 
and Gillingham, 2014; Rasmussen, 2001 for wind in Denmark; van Benthem et al., 2007 for Californian PV; Andresen, 2012 for offshore Norwegian wind). Others address how to design policy (Bardhan, 1971; Lehmann, 2013; Mazzola and McCardle, 1997), and what is the right instrument - whether to subsidize capacity (Andor and Voss, 2016) or support the production of the technology (Reichenbach and Requate, 2012). Few if any papers attempt to estimate the justified subsidy for specific technologies with their own characteristics. ${ }^{6}$ An earlier working paper (Newbery, 2017, a shortened version of which appeared as an appendix in Newbery, 2018) took a similar but simpler approach, but ignored future competition from other low-carbon options, and future post-saturation growth. The present paper points out the sensitivity of results to the details of the modeling assumptions.

Goulder and Mathei (2000) build an elegant but highly simplified global optimal abatement model in which abatement reduces $\mathrm{CO}_{2}$ emissions, whose cumulative stock must be kept below some critical level. Investment in $\mathrm{R} \& \mathrm{D}$ generates knowledge, as does cumulative abatement effort (learning-by-doing, LbD). If cost reductions come from R\&D alone, the optimal choice of abatement will be later when costs are lower, but if it comes from LbD, the impact on timing is ambiguous, although Grubb et al. (2002), in reviewing their model, note "their specific examples do yield stronger early mitigation with LbD". The model developed here is very partial (just the electricity sector) and ignores any impact on the carbon price (central to global energyenvironment models), but it asks whether it is desirable to accelerate or delay deployment in the presence of $\mathrm{LbD}$, and what might influence that choice.

\subsection{Relevant technology characteristics}

$\mathrm{PV}$ is a key low-carbon ${ }^{7}$ generation technology as it enjoys the highest rate of cost reduction and is already commercially viable in high insolation locations such as Mexico and Chile. It also has the highest sustained rate of growth of all renewable energy supplies, but it, like wind, has important characteristics that need to be taken into account in projecting future costs and benefits. First, PV and wind enjoy site-specific resources - not all locations are equally sunny or windy. Second, and as a result, they can potentially saturate the local market, so that efficient deployment involves moving to less attractive sites. Finally, the hours of sunlight limit total penetration. Wind is not constrained to daylight hours, and can be complementarity with PV, with higher outputs often in winter, but in some locations wind may peak inconveniently in late night hours (Hoste et al., 2011, figs 5, 6). As peak output in both cases is a multiple of

\footnotetext{
${ }^{6}$ Kalkuhl et al. (2012) presents a calibrated general equilibrium global model and gives graphs of optimal learning subsidies (fig. 5) for generic technologies.

${ }^{7}$ Although PV generation is zero-carbon making the modules is quite energy and potentially carbon intensive. Wider decarbonisation would reduce its manufacturing carbon footprint.
} 
average output, wide-area penetration is ultimately limited by the extent of excess renewable generation (Hirth, 2018). This paper develops techniques to handle all three characteristics, while an appendix discusses other low-carbon options like Carbon Capture and Storage (CCS) that avoid these limitations.

The model is as simple as possible consistent with capturing cannibalization and saturation, to provide simple formulae for justified subsidy rates that can be rapidly numerically evaluated. The global social cost-benefit formula accounts for important characteristics of electricity markets largely ignored in the learning/technology policy literature and allows a quick test for whether early acceleration or delay is appropriate.

The next section discusses the form and implications of learning-by-doing. Section 3 presents a simple model that captures the site-specific nature of PV or wind and its implication for future output. Section 4 presents the components and results of the social cost-benefit analysis, followed in section 5 by a method of determining the maximum justifiable learning subsidy. The appendices provide the evidence base for quantification, comparable results for other low-carbon technologies, and the more tedious derivations.

\section{Learning-by-doing cost reductions}

The key assumption is that past learning rates will continue. While there is uncertainty not only about past learning rates (Rubin et al., 2015) but clearly about future rates and even their attribution to deployment or R\&D (Jamasb, 2007; Nordhaus, 2014), ${ }^{8}$ figure 1 shows that learning rates for technologies like PV are impressive and persistent. The market for renewable technologies is intensely competitive, making it hard for manufacturers to capture these learning benefits, which primarily lower subsequent production costs.

The second case for supporting PV (and all low-carbon technologies) is that even in countries that have an explicit carbon price, such as the European Union's Emissions Trading System, the carbon price is well below any plausible estimate of the social cost of carbon - the present value of the future damage caused by a higher stock of greenhouse gases (Dolphin et al., 2016; US EPA, 2016). The social cost benefit analysis therefore needs to include the social cost of carbon.

\footnotetext{
${ }^{8}$ Gambhir et al. (2014) note the complex interactions between R\&D and deployment, with increased deployment stimulating more R\&D and vice versa, supporting the view that increments in cumulative capacity are the main factor driving down costs in later near-market stages.
} 


\subsection{Learning rates and cost reductions}

The simple one-factor learning model has the unit cost at date $t, c_{t}$ :

$$
c_{t}=a K_{t}^{-b}, \text { so } \frac{\Delta c}{c}=(1+\Delta K / K)^{-b}-1,
$$

where $K_{t}$ is cumulative production of units to date $t$, and $b$ measures the rate of cost reduction. (A list of symbols together with their assumed values is given in Table 1 below.) The learning rate, $\lambda$, is the reduction in unit cost for a doubling of capacity, so setting $\Delta K=K$ in (1), $\lambda=-\frac{\Delta c}{c}=1-2^{-b}$. For $\lambda=22 \%$, (ITRPV, 2016) $b=0.358$. The factor $b$ can then be used to estimate the future unit cost from (1). Over longer periods of time, it is implausible to assume that learning rates can continue until costs fall almost to zero. ${ }^{9}$ Equation (1) can be modified to allow for an irreducible minimum production cost, $c_{m}$.

Assumption 1 (cost) The unit cost, $c_{t}$, at date $t$, where $K_{t}$ is cumulative production of the units to date $t$, is

$$
c_{t}=c_{m}+a K_{t}^{-b}=c_{0}\left(\phi+(1-\phi)\left(\frac{K_{t}}{K_{0}}\right)^{-b}\right),
$$

where $\phi \equiv c_{m} / c_{0}$ is the ratio of the minimum ultimate cost, $c_{m}$, to that at date zero.

Initially, $\Delta c /\left(c-c_{m}\right) \simeq \Delta c / c$, and the estimated learning rate will not be much affected if $\phi$ is small, but as costs fall the difference can become appreciable. If installed capacity is growing at rate $g$ costs will be initially falling at rate $b g$.

The learning formulae, (1) or (2), imply that the cost of delivering learning is lowest when the stock of knowledge is lowest. The subsidy cost of doubling cumulative production from $1 \mathrm{GW}$ is far lower than doubling it from $100 \mathrm{GW}$. That suggests the globally optimal solution is either to do no further investment (if the technology will never be competitive), or to accelerate investment at the maximum possible rate. In mathematical terms, the optimal solution would be 'bang-bang' - to immediately jump to the optimal cumulative production that delivers competitive PV from here on. As Neuhoff (2008) cogently argued, this strategy is implausible for at least two reasons. The first is that scaling up production capacity takes time, and second, more fundamentally, learning itself takes both experience and time for it to disseminate and be incorporated into best practice. Indeed, the two-factor model stressing the importance of R\&D would likely find it hard to discriminate between $R \& D$ and the elapse of time for dissemination. It is often remarked that Silicon Valley is more innovative than Japan because of the high turnover of staff carrying their knowledge to competing firms, in contrast to life-time employment practices in Japan that make such people-mediated knowledge transfer less likely (McMillan, 1984). These limitations are summarised in

\footnotetext{
${ }^{9}$ King et al. (2015) note that "The IEA believe that photo-voltaic panels will eventually reach a floor price, but new truly disruptive technologies, such as plastic photovoltaics, could continue the downward fall in price."
} 
Assumption A2 (growth) There is a maximum feasible rate of expansion of cumulative capacity of rate $g$.

The global rate of growth of cumulative PV capacity has been at or above $30 \%$ since $1992,{ }^{10}$ and this may well be near the plausible limit to sustained growth. Future growth will be limited by the size of the resource, the fact that the sun does not shine at night (at least, in any one location), saturation (with curtailment) of local markets constrained by interconnection, and the rate of growth of demand for total electricity. Global saturation will occur at date $T$ (determined in A4 below) when all sites at which investment is socially profitable have been exploited. After that date investment opportunities are limited by the rate of growth of the total market demand for electricity.

While the argument for maximizing the rate of installation looks persuasive, it needs examination, as future carbon prices will be higher, raising the value of future decarbonization relative to the present. In addition, increasing cumulative capacity raises the cost of each doubling substantially, and may eventually argue for reducing the rate of investment.

Hypothesis $\mathbf{H}$ The globally optimal investment strategy is to invest at the maximum growth rate $g$, until saturation at date $T$, at which point $P V$ growth is constrained by the global rate of increase of electricity demand.

This can be tested by checking that increasing the rate of investment above this trajectory at any moment increases the net social value. This is done in section 5.1 below, which supports the hypothesis for cases of PV with high learning and growth rates, but not for cases of lower learning and growth rates, nor is the hypothesis confirmed for wind, with lower learning and growth rates. A more sophisticated approach would be to set the problem up as a dynamic optimization problem (as in Goulder and Mathai, 2000), or, more ambitiously, to make the learning curve stochastic and use a Bellman approach, as in Mazzola and McCardie (1997), but these can only be solved numerically, reducing their transparency.

\section{A simple model}

The simplest model to represent the aspirations of the Global Apollo Programme (King et al., 2015) has a central planner allocating investment to its most attractive location at each moment. ${ }^{11}$ The model starts at date $t=0$ with an inherited stock of capacity, $K_{0}$. Future capacity

${ }^{10} \mathrm{https}$ //en.wikipedia.org/wiki/Growth_of_photovoltaics

${ }^{11}$ This social optimum approach is standard in global climate change mitigation models such as Goulder and Mathai (2000), although practical policies will need to take account of feasible and probably incomplete global coalitions. 
depends on the time path of gross investment, $I_{t}$, whose unit cost is $c_{t}$. From A2 and $\mathrm{H}, I_{t}$ grows at rate $g$ until $T$, so $I_{0}=g K_{0}$. At $T$ its share of total demand reaches its maximum. Thereafter capacity grows at rate $m$ equal to global electricity growth as all existing capacity can continue to expand to meet the growing local markets and thus expand at the demand growth rate:

$$
K_{u}=K_{0} e^{g u}, \quad u \leq T, \quad K_{u}=K_{T} e^{m(u-T)}=K_{0} e^{(g-m) T} e^{m u}, \quad u>T .
$$

For simplicity, panels are assumed to last indefinitely, so that cumulative capacity, $K_{t}$, is equal to current capacity, $k_{t} .{ }^{12}$ Growth will continue until the market is saturated by installed capacity $K_{T}$ at date $T$, determined by $K_{T}$ in Assumption A4, so $T$ is determined by $g$.

\subsection{Sequencing investment}

Annual output at a specific site depends on $h$, equivalent full hours output per year. $h$ depends on location and will not vary with time. As local penetration as a share of the effective market increases (limited by interconnection capacity) after a period peak PV output will displace all flexible fossil generation in some hours, resulting in curtailment. The local price decline is gradual until it becomes necessary to curtail PV output, after which the fall in sharp (Denholm \& Margolis, 2007). ${ }^{13}$

Once a site has been saturated, investment would shift to the next most favourable site. The margin of investment can be roughly approximated by $K$, so the capacity factor at "location" $K$ can be written $h(K)$.

Assumption A3 (capacity factor) The capacity factor at the location defined by $K_{t}$ is

$$
h\left(K_{t}\right)=h_{0}\left(\frac{K_{t}}{K_{0}}\right)^{-\zeta}
$$

If $K$ grows at $g$, the capacity factor will fall at rate $\zeta g$. Global saturation is defined by the least attractive location that is still socially profitable, when $h\left(K_{t}\right)$ has fallen to to $h\left(K_{T}\right)=h_{T}$ (defined by "location" $K_{T}$ ):

Assumption $\mathbf{A} 4$ (saturation) The date of global saturation, $T$, is defined by $h_{T}$, from $h_{T} / h_{0}=e^{-\zeta g T}$ or $T=\ln \left(h_{0} / h_{T}\right) /(\zeta g)$, so lower values of g give higher values of $T$.

\footnotetext{
${ }^{12} \mathrm{With}$ exponential decay of panels at rate $\delta, k_{t}=\theta K_{t}, \theta=1 /(1+\delta / g)$. At plausible decay rates $(\delta<1 \%$, Jordan and Kurtz, 2012) and growth rates $(g=25 \%) \theta \simeq 1$, making this refinement unimportant and so ignored. After date $T$ degradation will need to be included to avoid implausible indefinite future benefits.

${ }^{13}$ Hirth (2018) notes that $40 \%$ of the drop in German spot prices between 2008 and 2015 was caused by the increase in renewable energy. In addition to the curtailment modeled in this paper, wholesale prices can fall because of the merit order effect, which, with very diverse generating plant, can be pronounced (Hirth, 2018; Sensfuß et al., 2008). The merit order effect is modeled in section 4.1.
} 


\subsection{Determining PV output}

Incremental PV output after installing capacity $K_{u}$ to date $u$ will be determined by investment at that date, $I_{u}=d K_{u} / d u$. This gives a vintage model in which cost, $c_{u}$, and performance, $h\left(K_{u}\right)$, are locked in at date $u$, as in Rasmussen (2001), in contrast to simpler models of disembodied progress. Incremental output from "vintage" $K_{u}$ will be $y\left(K_{u}\right)=h\left(K_{u}\right) d K_{u} / d u$ and from A3, total output attributable to investment starting at date $t$ when initial capacity is $K_{t}$ up to the date $u$ when the capacity has risen to $K_{u}$ will be $Y_{t, u}$ :

$$
\begin{aligned}
Y_{t, u} & \left.=\int_{K_{t}}^{K_{u}} h\left(K_{v}\right) \frac{d K_{v}}{d v} d v=h_{0} \int_{K_{t}}^{K_{u}}\left(\frac{x}{K_{0}}\right)^{-\zeta} d x\right), \\
& =h_{0} K_{0}\left(\frac{\left(K_{u} / K_{0}\right)^{1-\zeta}-\left(K_{t} / K_{0}\right)^{1-\zeta}}{1-\zeta}\right) .
\end{aligned}
$$

At date $T$ the growth of capacity reaches the point of market saturation, and thereafter is constrained by the growth of electricity demand. The assumption is that all existing capacity now expands with its characteristic capacity factor at this market growth rate $m$. Although initially capacity grows at rate $g$ (although output grows less rapidly), after saturation both output and capacity are constrained to grow at rate $m$. Output at date $u$ attributable to investment from date $t$ will be

$$
Y_{t, u}=h_{0} K_{0}\left(\frac{e^{g(1-\zeta) u}-e^{g(1-\zeta) t}}{1-\zeta}\right), \quad t<u \leq T, \quad=Y_{t, T} e^{m(u-T)}, \quad u>T,
$$

where

$$
Y_{t, T}=h_{0} K_{0}\left(\frac{e^{g(1-\zeta) T}-e^{g(1-\zeta) t}}{1-\zeta}\right)
$$

Total output at date $t$ is incremental output plus initial output, $Y_{0}=h_{0} K_{0}$, or $Y_{t}=$ $Y_{0}\left(e^{g(1-\zeta) t}-\zeta\right) /(1-\zeta)$, and this can be used to determine the penetration at any subsequent date. Thus if $Y_{T_{1}} / Y_{T}=\left(e^{g(1-\zeta) T_{1}}-\zeta\right) /\left(e^{g(1-\zeta) T}-\zeta\right)=\theta$, then

$$
e^{g(1-\zeta) T_{1}}=\theta e^{g(1-\zeta) T}+(1-\theta) \zeta
$$

\subsection{The social value of PV capacity}

Fossil generation cannot be financed by pricing at variable costs alone, requiring the equivalent of a capacity payment (equivalent to a demand-side scarcity payment) to ensure that enough capacity is commercially viable to deliver the reliability standard. The capacity payment can be determined in a Power Purchase Agreement (PPA) specifying the energy price and capacity payment, or in a decentralized market by a capacity auction or its equivalent, or, in an energyonly market, by scarcity pricing when capacity is tight. Plant in our model effectively holds a 
PPA with the spot price equalling the System Marginal Cost, ${ }^{14}$ and capacity paid its equivalent firm capacity.

The derating factor of $\mathrm{PV}, \tau$, is the amount of avoided derated fossil capacity needed to meet the reliability standard per unit of capacity (typically a percentage). In each summer-peaking location, as more PV capacity is installed, its marginal capacity contribution falls to zero as more output is curtailed. However, its average local contribution compared to the counterfactual of zero PV will be positive. In winter-peaking systems lacking seasonal storage, i.e. in most northern countries such as the UK, PV offers negligible contribution to reliable capacity, and there $\tau=0$. In summer-peaking systems (with high air-conditioning load) and at low local penetration rates, $\tau$ could be as high as $30 \%$.

Assumption A5 (derating) The initial (zero penetration) derating factor for solar $P V$ at location $K_{j}$ is $\tau_{j}=\tau_{0}\left(K_{j} / K_{0}\right)^{-\sigma}$ in summer peaking systems. With increased penetration in location $j$ the capacity credit remains constant for the first third of final penetration there, when it falls linearly to the point where the marginal contribution to peak demand falls to zero. ${ }^{15}$ The effective (average) derating factor for investment at location $K$ per unit is

$$
\frac{2 \tau_{0}}{3}\left(\frac{K}{K_{0}}\right)^{-\sigma}
$$

\section{Social cost-benefit analysis of a PV programme}

Any policy proposal, such as subsidizing PV, requires a counterfactual - what would have happened absent the policy. Given the premise of the Global Apollo Programme (King et al., 2015), if PV were not considered a potential solution to decarbonizing electricity, some other set of technologies would have been deployed, e.g. some combination of other low-carbon technologies such as wind, nuclear power and/or carbon capture and storage applied to fossil generation. The least favourable assumption for supporting $\mathrm{PV}$ is that by some date $N$ these alternatives could have met any additional decarbonization contribution that PV might have offered at a comparable cost. In the same spirit, after $N$, PV investment produces no higher spill-overs than alternative investments, and so subsequent learning benefits can be ignored. However, it is no

\footnotetext{
${ }^{14} \mathrm{As} \quad$ in the Single Electricity Market of the island of Ireland - see e.g. p7 of https://www.semcommittee.com/sites/semcommittee.com/files/media-files/SEM-17070\%20MMU\%20Public\%20Report\%20Q2\%202017_0.pdf

${ }^{15}$ Ignoring the terms in $K$, the formula for the capacity factor is $y=\tau_{0}, 0 \leq x \leq \frac{1}{3}, y=\frac{3}{2} \tau_{0}(1-x), \frac{1}{3} \leq x \leq 1$, where $y(x)$ is the capacity factor when a fraction $x$ of the local zone is saturated. The average capacity factor is then $\int_{0}^{1} y d x=2 \tau_{0} / 3$. The exact shape of the declining capacity factor caused by curtailment is not critical, given the modest contribution of the capacity credit; the point is that the average contribution lies between the uncurtailed and the fully curtailed value.
} 
longer credible to assume no degradation after $N$, and as there is no carbon benefit, technical progress of all new low-carbon technologies is assumed to drive the value of displaced power down at rate $\mu$.

Assumption A6 (post saturation) After $N, K_{N}$ will decay at rate $\delta$ and disappear after $L$ years, while displaced electricity prices will fall at rate $\mu$.

Assumption A7 (horizon) After N, PV can claim no external benefits, but the installed capacity at date $N$ will continue to displace generation and earn social profits until it reaches the end of its life.

\subsection{Valuing PV output}

The net value of PV will be the System Marginal Cost (SMC) of fossil fuel displaced less the extra balancing costs required by the $\mathrm{PV}$, which together make up $p_{t}$, plus the social cost of the $\mathrm{CO}_{2}$ avoided, $\gamma_{t}$ per unit of displaced fossil generation, to give a total value of $p_{t}+\gamma_{t}$ per MWh. As with the capacity credit, $p_{t}$ may decline with increasing local PV penetration (the merit-order effect) and hence will be a function of $K$. The social value of displaced carbon will increase at rate $i$, close to the social discount rate, $r .{ }^{16}$ If we assume a similar formulation as that in A5, $p(K)=p_{0}\left(K / K_{0}\right)^{-\xi}$, then $p_{t}=p_{0} e^{-g \xi t}$. It will be convenient to set $g \xi=\pi$, noting that $\pi$ is proportional to $g$, while $p\left(K_{T}\right)=p_{T}$ is independent of $g$. The social cost of the $\mathrm{CO}_{2}$ avoided, $\gamma_{t}$ per unit of displaced fossil generation will depend on the fuel displaced. The case least favourable to supporting $\mathrm{PV}$ is to suppose that an adequate $\mathrm{CO}_{2}$ price has made efficient gas-fired turbines the marginal flexible fuel displaced by PV. ${ }^{17}$ If gas-fired combined cycle turbines (CCGTs) are always at the margin when PV produces, its SRMC sets the price. However, the fraction of the time that fossil is at the margin will gradually decrease as other low-carbon technologies are deployed, so the effective average price realized will gradually fall - an effect magnified by any merit-order effect from diversity in the fossil generation mix.

Assumption A8 (output value) The social cost of carbon per $M W_{e}$ of fossil generation displaced at date $t$ is $\gamma_{t}$ per $M W h_{e}$, rising at rate $i$ to date $N$, and the $P V$ output-weighted annual average extra variable fossil cost (fuel + the excess of the fossil variable O\&M over the $P V$ variable O\&M less any extra balancing costs required to manage the $P V)$ is $p_{t}=p_{0} e^{-\pi t}$,

\footnotetext{
${ }^{16}$ This is a standard result from optimal climate mitigation - see e.g. Goulder and Mathai (2000).
}

${ }^{17}$ Subscript $e$ refers to electricity (in contrast to the energy content of fuel, indicated by subscript $t h$ ). If PV displaces efficient combined cycle gas turbines the carbon intensity will be roughly 0.4 tonnes $\mathrm{CO}_{2} / \mathrm{MWh}_{e}$ (Bass et al. 2011). Thus if the social cost of carbon is $\$ 37.5 /$ tonne $\mathrm{CO}_{2}, \gamma=\$ 15 / \mathrm{MWh}_{e}$. In many parts of the world the fuel displaced will be coal, which has twice the emissions factor of gas. 
where $\pi=g \xi$, and $\xi$ is a constant. At date $N$ its unit value is $s_{N}=p_{0} e^{-\pi N}+\gamma_{0} e^{i N} .{ }^{18}$

A social cost-benefit analysis of the trajectory calculates the investment cost to date $T$, after which the rate of growth falls to that of total electricity demand, dramatically lowering the subsequent learning benefits. For lower rates of growth, $T>N$, and after $N$ the benefits from future investment can be ignored. In both cases installed capacity at $N$ will continue to displace fossil generation.

\subsection{The cost of the investment strategy}

The total present discounted value (PDV) of investment cost from date $t$ (and its relation to initial capacity $K_{0}$ ), at the social discount rate $r$ is:

$$
\frac{C_{t}}{K_{0}}=\int_{t}^{\operatorname{Min}(T, N)} c_{u} \frac{I_{u}}{K_{0}} e^{-r(u-t)} d u+\frac{K_{T}}{K_{0}} \int_{M i n(T, N)}^{N} c_{u} \frac{I_{u}}{K_{T}} e^{-r(u-t)} d u
$$

The integral is evaluated in Appendix B. In terms of the hypothesis that early investment is cheaper than later

$$
\left.\frac{d}{d t}\left(\frac{C_{t}}{K_{0}}\right)\right|_{t=0}=r \frac{C_{0}}{K_{0}}-g c_{0}
$$

which is typically positive.

\subsection{The capacity credit for PV}

The derating factor of $\mathrm{PV}, \tau$, is only positive in summer-peaking systems, which will eventually become saturated, after which time investment would relocate to winter-peaking sites. The assumption is that when all sites are saturated at $T$, a fraction $\theta$ of output will then be supplied by summer-peaking sites.

Assumption A9 (summer peaking) Under optimal deployment, summer peaking sites will be developed first, up to $K_{T_{1}}$, which will occur at date $T_{1}$ determined by $Y_{T_{1}}$, itself determined by the absorptive capacity of summer peaking systems (i.e. when summer peaking sites are saturated).

${ }^{18}$ van Bentham et al. (2007) assume that gas prices rise at $1 \%$ real p.a., presumably as it is an exhaustible resource. Countering that, decarbonization puts downward pressure on fossil fuel prices. They also assume that the carbon price increases over time but that the $\mathrm{CO}_{2}$ released per marginal kilowatt hour of electricity decreases correspondingly over time, so that the dollar value of the environmental externality remains constant. As the social cost of $\mathrm{CO}_{2}$ rises at close to the social discount rate, this would require an increasing share of less carbon-intensive marginal sources over time as coal and/or oil units are retired. The assumed rate of increase of $\mathrm{CO}_{2}$ per $\mathrm{MWh}$ $\mathrm{PV}$ reflects some of these effects, while the fall in the fossil cost at rate $\pi$ captures the rest of the decarbonization. For the representative parameters in Table 1 the effects lead to an almost constant net value of renwables, $p_{t}+\gamma_{t}$. 
If $Y_{T_{1}} / Y_{T}=\theta$, then from (7), $T_{1}=\ln \left(\theta e^{g(1-\zeta) T}+(1-\theta) \zeta\right) /(g(1-\zeta))$. At any date $t<T_{1}$ the total present discounted value $(\mathrm{PDV})$ of future capacity credits under steady growth when the capacity payment is $P(\$ / \mathrm{MWyr})$ and $\tau(K)$ is given by $(8)$ is

$$
\begin{aligned}
\frac{\Pi_{t}}{K_{0}} & =\frac{2}{3} P \int_{t}^{T_{1}} e^{-r(u-t)} \frac{I_{u}}{K_{0}} \tau_{0} e^{-\sigma g u} d u \\
& =\frac{2}{3} g \tau_{0} P e^{r t} \frac{\left(e^{((1-\sigma) g-r) T_{1}}-e^{((1-\sigma) g-r) t}\right)}{(1-\sigma) g-r}
\end{aligned}
$$

\subsection{The social value of post-saturation PV}

Given A5-8 the PDV of output after date $N, V_{t}$, attributable to investment from date $t$, is, if $N \geq T$ and the unit value of output declines at $\mu$ and output $Y_{t, u}$ declines at rate $\delta$ after $N$,

$$
\begin{aligned}
\frac{V_{t}}{K_{0}} & =e^{-r(N-t)} s_{N} \frac{Y_{t, T} e^{m(N-T)}}{K_{0}} \int_{0}^{L} e^{-(\mu+\delta+r) u} d u \\
& =h_{0} s_{N} e^{r t}\left(\frac{e^{g(1-\zeta) T}-e^{g(1-\zeta) t}}{1-\zeta}\right) e^{(m-r) N-m T}\left(\frac{1-e^{-(r+\delta+\mu) L}}{r+\delta+\mu}\right)
\end{aligned}
$$

If $N<T, T$ is replaced by $N$. Note that there is no capacity credit after $T_{1}<N$.

\subsection{The capacity credit for wind}

Wind contributes a positive capacity credit that is typically higher in winter-peaking systems. In Britain Ofgem cites wind's Equivalent Firm Capacity (EFC) as 17-24\%, when the on-shore wind capacity factor is $26 \%$ and that for off-shore is $37 \% .{ }^{19}$ If the two EFCs are interpreted as on-shore and off-shore then the EFCs are both $65 \%$ of the capacity factor. In the island of Ireland the EFC is a function of penetration and market size, and falls from $71 \%$ of the capacity factor at zero penetration to about $33 \%$ when installed capacity exceeds domestic peak demand. ${ }^{20}$ Figures for North America for EFCs range from 3\%-30\% with California at 24\%. ${ }^{21}$ That suggests taking an average capacity credit of $50 \%$ of the capacity factor, $h(K)$, so the annual credit at location $K$ is $P h(K) / 17,520$, as there are 8,760 hours for the full capacity credit. The total credit for the cumulative stock can be written as $P Y(K) / 17,520$, from (5) so the total PDV is

$$
\Pi_{w t}=\frac{P e^{r t}}{17,520}\left(\int_{t}^{M i n(T, N)} e^{-r u} Y_{t, u} d u+Y_{t, T} \int_{M i n(T, N)}^{N} e^{m(u-T)} e^{-r u} d u\right),
$$

evaluated in Appendix B.

\footnotetext{
19 www.ofgem.gov.uk/ofgem-publications/75232/electricity-capacity-assessment-report-2013.pdf

${ }^{20}$ http://www.soni.ltd.uk/media/documents/Operations/CapacityStatements/All\%20Island\%20Generation\%

20Capacity\%20Statement\%202015\%20-\%202024.pdf

${ }^{21}$ https://www.bchydro.com/content/dam/hydro/medialib/internet/documents/info/pdf/info_iep_dependable_capacity_and_firm_ene
} 


\subsection{Total social benefits}

The displaced generation saving benefits from $t$ to the earlier of date $N$ or $T$ are the sum of the discounted values of the output of PV times the value of the displaced fossil energy (including its carbon cost) up to the first date when it is expanding at its maximal rate, and a second discounted sum when output is expanding at rate $m$ :

$$
F_{t}=\int_{t}^{\operatorname{Min}(T, N)} e^{-r(u-t)} Y_{t, u}\left(p_{u}+\gamma_{u}\right) d u+Y_{t, T} e^{r t-m T} \int_{M i n(T, N)}^{N} e^{(m-r) u}\left(p_{u}+\gamma_{u}\right) d u .
$$

This is evaluated in Appendix B. Total social benefits are the sum of three elements: $S_{t}=F_{t}+$ $\Pi_{t}+V_{t}$, and the question is whether $S_{t} / K_{0}>C_{t} / K_{0}$. The net (relative) benefit is $S_{t} / K_{0}-C_{t} / K_{0}$, sometimes (potentially misleadingly) summarized by the dimensionless benefit-cost ratio, $S_{t} / C_{t}$.

\subsection{Is it desirable to moderate deployment?}

The Hypothesis suggested that the optimal policy was to invest at the maximum feasible rate until saturation, but the benefits of future learning fall as date $N$ approaches, after which by assumption future learning is no more valuable than for any alternative low-carbon option. The hypothesis can be tested by increasing $g$ at date 0 by a small increment and comparing the net relative benefit numerically, and for subsequent dates $t>0$, by evaluating $S_{t} / K_{t}-C_{t} / K_{t}$ and repeating this small deviation.

\section{The size of the potentially justified subsidy}

If supporting PV (or wind) is socially justified, the next question is to determine the maximum justified learning subsidy to stimulate its adoption. The actual learning subsidy required may be considerably less, and is likely best determined through a tender auction, for which a ceiling - this maximum - is needed. (Any carbon credit for displacing fossil fuel is assumed to be addressed separately.) This maximum subsidy is the value of future cost reductions, discounting at the social discount rate, $r$. Future investment costs at date $u$ are $c_{u} I_{u}$.

The net present discounted cost of future investment at date $t, A_{t}$, is $\int_{t}^{N} c_{u} I_{u} e^{-r(u-t)}$, assuming that there are no learning benefits after date $N$. Allowing for the change in the capacity growth rate at date $T$ (apart from a possible deviation at date $t$, and with a sudden drop in the investment required to maintain lower growth at $T$ ), the NPV will be, after substituting for $c_{u}$ 
from (2), is, for $t<T:^{22}$

$A_{t}=c_{0} \int_{t}^{M i n(T, N)} I_{u}\left(\phi+(1-\phi)\left(\frac{K_{u}}{K_{0}}\right)^{-b}\right) e^{-r(u-t)} d u+c_{0} \int_{M i n(T, N)}^{N} I_{u}\left(\phi+(1-\phi)\left(\frac{K_{u}}{K_{0}}\right)^{-b}\right) e^{-r(u-t)} d u$.

$K_{u}=K_{0} e^{g u}$ until $T$, and thereafter $K_{u}=K_{0} e^{(g-m) T} e^{m u}$. A change in current investment, $d I_{t}$, will change all future values of $K_{u}$ by $d I_{t}$, so $d K_{u} / d I_{t}=1, u>t$, but $I_{u}$ for $u>t$ remains unchanged. Differentiating (14):

$$
\frac{d A_{t}}{d I_{t}}=c_{t}-c_{0} b(1-\phi) e^{r t}\left(\begin{array}{c}
\int_{t}^{\operatorname{Min}(T(K), N)}\left(\frac{K_{u}}{K_{0}}\right)^{-b-1}\left(\frac{I_{0} e^{g u}}{K_{0}}\right) e^{-r u} d u \\
\left.+\int_{\operatorname{Min}(T(K), N)}^{N}\left(\frac{K_{u}}{K_{0}}\right)^{-b-1}\right)\left(\frac{I_{u}}{K_{0}}\right) e^{-r u} d u
\end{array}\right) .
$$

The two last terms are the spill-over benefits, $B_{t}$. Note that the integral limit $T$ is a function of $K_{T}$ and hence $I_{0}$ from Assumption 4. The proportional benefit $B_{t} / c_{0}$ is, after substituting for $I_{u}=d K_{u} / d u$ from $(3)$,

$$
\frac{B_{t}}{c_{0}}=b(1-\phi) e^{r t}\left(g \int_{t}^{M i n(T(K), N)} e^{-(b g+r) u} d u+m e^{-b(g-m) T} \int_{\operatorname{Min}(T(K), N)}^{N} e^{-(b m+r) u} d u\right),
$$

as the derivatives w.r.t. the integral terms $T$ cancel. Note that if there is no learning, then $b=0$, and there is no justified subsidy, as expected. The spill-over benefit in (15) is thus:

$$
\frac{B_{t}}{c_{0}}=(1-\phi) e^{r t}\left(\frac{e^{-(b g+r) t}-e^{-(b g+r) T}}{1+r /(b g)}+e^{-b(g-m) T} \frac{e^{-(b m+r) T}-e^{-(b m+r) N}}{1+r /(b m)}\right) .
$$

As $B_{t}$ is decreasing in $t$, the absolute size of the spill-over benefit is larger in earlier periods. Although the spill-over benefits were higher at earlier dates, the cost net of the spill-over benefit at date $t$ is $c_{t}-B_{t}$ and $c_{t}$ was also higher in the past, as figure 2 shows (the base case has $\left.c_{m} / c_{0}=25 \%\right)$. Appendix B shows that at some time in the past the spill-over benefits more than covered the up-front investment costs, but this could have been so far ago as to be irrelevant. Table 1 shows that over the period of significant investment, the net cost was still falling, using the results of the next section.

\subsection{Calculations}

Table 1 presents the results for varying parameter values based on the calibrations set out in Appendix A (and giving a variety of values reflecting the uncertainties surrounding many of these parameter values). All the calculations assume that $c_{0}$ for $\mathrm{PV}$ is $\$ 1,050 / \mathrm{kW}_{p}$ and for wind is $\$ 1,560 / \mathrm{kW}$ in $2015(t=0)$, the rate of ultimate post-saturation growth in $(3), m=1.75 \%$, the de-rating values in (8) are $\sigma=0.4$ and the initial de-rating factor for $\mathrm{PV}, \tau_{0}=30 \%$. The capacity

${ }^{22}$ If $N>t>T$, the first term is zero and the lower limit of the second integral is $t$, and $T$ is replaced by $t$ in (16). 


\section{Cost and subsidy per kWp}

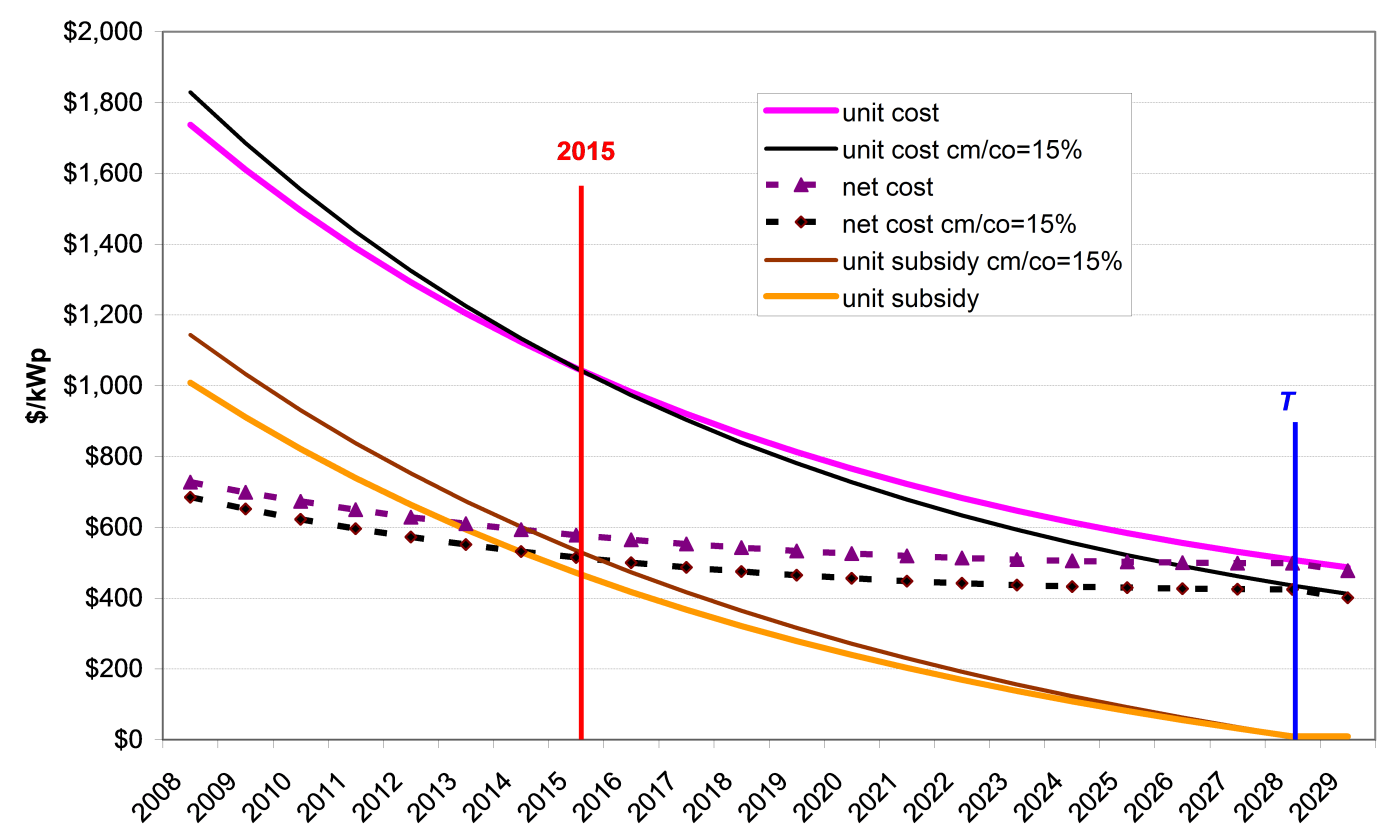

Figure 2: Cost and subsidy per $\mathrm{KW}_{p}$

payment in (10), $P=\$ 75,000 / \mathrm{MWyr}$, the A6 post-saturation rate of fall in value, $\mu=1 \%$ and the degradation rate $\delta=2 \%$. The 2015 social cost of carbon, SCC, $\gamma_{0}$, is $\$ 15 / \mathrm{MWh}_{e}$ growing at $i=1.0 \%$ p.a. ${ }^{23}$ the discount rate $r=3 \%$, and the 2015 SRMC $p_{0}=\$ 35 / \mathrm{MWh}$, while the value of $\xi=0.4$, so $\pi=g \xi$, as in A8. The highlighted cells indicate which parameters have changed with the consequential parameter changes. The top lines give the technology, showing wind with a lower $\lambda$ that PV. ITRPV (2016) gives the learning rate for PV as $22 \%$ but Rubin et al. (2015) reduce this to $18 \%$ in the two-factor model, ${ }^{24}$ so both values are tested. IRENA (2016) gives on-shore wind investment cost learning rates as $7-12 \%$ but Rubin et al. (2015) give slightly higher values (see Appendix C).

The first point to note is that the fourth line up from the bottom allows a test of whether raising the rate of growth, $g$, by $1 \%$ is beneficial. The correct test is whether it raises the net social benefit, which involves comparing the fourth and fifth lines from the bottom. Raising the growth rate is beneficial in the PV cases except for Col F (with a lower $g$ and $\lambda$ than the base case in Col A, although it can be directly compared with Col E with the same $\lambda$ ). For the wind cases, Cols H-J, only Col I, with high $g$ and $\lambda$, benefits from a higher $g$, while Col J shows that

${ }^{23}$ This is taking a pessimistically low value of both the SCC and its growth rate.

${ }^{24}$ The other factor is R\&D, although much of that will be stimulated by the growth in demand, so including R\&D as a separate explanatory factor likely understates the benefit of expanding cumulative capacity. 


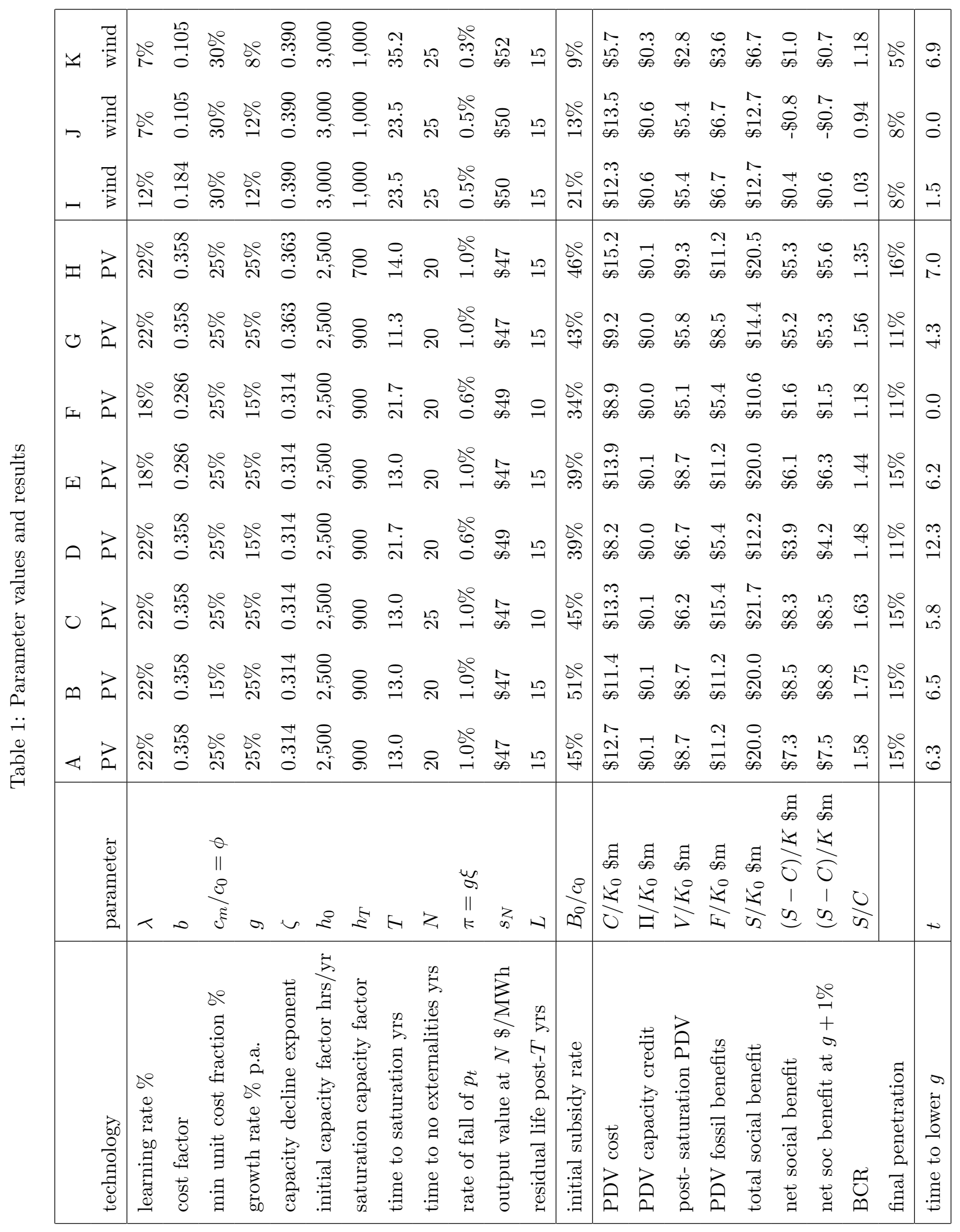


continuing at $g=12 \%$ with a lower learning rate, $\lambda$, is socially unprofitable. Comparing Cols $\mathrm{J}$ and $\mathrm{K}$, it is clear that lowering $g$ from $12 \%$ to $8 \%$ raises the net social benefit (to a positive level), and there is an intermediate optimal rate of (steady) growth.

The evidence thus refutes the Hypothesis that the optimal rate is always the maximal rate. This raises the question of why the Hypothesis appears to hold in most cases for PV but not for wind. In the case of PV the initial installed capacity is modest, so the cost of expansion is not so high. High rates of learning and high rates of expansion mean that the future costs are driven down more rapidly and can be secured sooner than in the converse case, lowering the current cost of delivering future benefits. In the case of wind the initial installed base is now so large that the cost of doubling installed capacity becomes very large while the cost reduction (with the lower learning rate) is smaller, and so delaying until the social cost of carbon has risen sufficiently to overcome the higher cost of wind has higher value.

Comparing across Columns, we find, unsurprisingly, Col B shows that lowering the minimum $\operatorname{cost} c_{m}$ raises the justified subsidy and the net social benefit per MW of initial capacity (in 2015). Again unsurprisingly, extending the time before there are no external benefits, $N$, increases the net social benefit, while lowering the learning rate $\lambda$, (Col E vs. Col A) lowers net social benefit. Lowering the post saturation lifetime, $L$, reduces the net social benefit. Col G vs Col A shows that increasing the capacity decline exponent $\zeta$ lowers the net social benefit by reducing the time to saturation (and the eventual saturation shown in the penultimate line), while Col $\mathrm{H}$ holds $\zeta$ at the same level as col $\mathrm{G}$ but reduces the saturation capacity factor from 900 hrs to $700 \mathrm{hrs}$, increasing the net social benefit slightly as it takes longer to reach saturation, by which time the penetration at saturation (the penultimate line) has risen from $11 \%$ to $16 \%$. Evidently, calibrating the model's parameters is a delicate matter and needs careful thought but it is simple to vary each parameter to assess its effect.

The last line shows the effect of starting on the expansion plan later to find the date, $t$, at which it is no longer desirable to raise the rate of growth (or to find the date at which the net social benefit from then on falls to zero). In most cases there is a later date at which the growth rate should be lowered. Together with evidence on the effects of increasing $g$, it is more plausible that the optimal investment path may have an initial growth rate at or below the maximal rate, with gradually falling growth rate as the learning externalities become lower and the costs of achieving them at higher scales becomes larger. Ignoring this refinement means that the estimated net social benefits are under-estimated, as an optimal path would improve on this suboptimal constant growth path.

Although the value of the discount rate, $r$, was held constant in Table 1, it is clearly important, and if $r$ is raised from $3 \%$ to $5 \%$, the net social benefit for Col A data falls from $\$ 7.3$ 
million to $\$ 3.3 \mathrm{~m}$, and at $r=8 \%$ to $\$ 0.8 \mathrm{~m}$. with a Benefit-Cost Ratio (BCR) of 1.02 (as would be expected). The rate of escalation of the carbon price, $i$, was also held constant at $1 \%$, but raising it to $2.9 \%$ (close to the social discount rate) increases the net social benefit in the Col A case to $\$ 10.1 \mathrm{~m}$. with a BCR of 1.8 . Similarly, raising $\gamma_{0}$ (but keeping $i=1 \%$ ) to $\$ 25 / \mathrm{MWh}_{e}$ raises the net social benefit of Col A to $\$ 12.3 \mathrm{~m}$. (again in the expected direction).

The final three columns ( $\mathrm{H}$ to $\mathrm{K}$ ) give results for wind (based on values given in Appendix C). As learning and growth rates are lower so are the BCRs, although higher capacity factors and capacity credits alleviate the impact. At low learning and a lower growth rate, $g$, of $8 \%$, the net benefits become negative (although raising the rate of growth has a beneficial impact as Col K shows).

To give a sense of the fraction of the cost that could be justified as a subsidy at date $t=0$, Table 1 gives the justified subsidy rate in 2015, so in $\mathrm{Col} \mathrm{A} B_{0} / c_{0}=45 \%$. At $g=15 \%$, (Col D) $T=21.7$ yrs which is greater than $N$ at 20 years, so learning and other benefits cease before full saturation. As a result, the subsidy falls to $39 \%$ of the cost. As the learning rate falls, so does the subsidy, so if $\lambda=18 \%$, ( $\mathrm{Col} \mathrm{E}$ vs $\mathrm{Col} \mathrm{A}) B_{0} / c_{0}=39 \%$. The results are also sensitive to the existence of a minimum feasible unit cost, $c_{m}$, in (2), and figure 2 shows the subsidy rates and the unit costs for two values of $c_{m} / c_{0}$. The two alternative unit cost curves cross at the calibration date, $t=0$ (2015). Note that for $N>t>T$ the first term in (16) is zero and the second term has $t$ in place of $T$, with a sharp decrease in the rate of fall of unit costs after $T$.

\subsection{Individual country contributions to the public good}

It is possible to compute the value of each country's contribution to reducing future costs by its current and previous investment, either roughly or more accurately. The rough estimate takes the estimated unit cost $c_{t}$ from (2) and the amount of capacity added in that year, using (17) to estimate the spill-over benefit, using the assumed growth rate, $g$ and learning rate, $\lambda$ of Col A. That underestimates the growth rates up to 2015 and hence underestimates the present value of the spill-over benefit. Recent cost declines have if anything been faster than average, judging from Figure 1, which might suggest a higher learning rate. However, some of that cost fall may be competitive shading of margins rather than genuine cost reductions, so there is as yet no compelling evidence that learning is accelerating. Working back from the current cost to earlier costs using (2) might undervalue those costs and hence the learning benefits, again erring on the conservative side. A more accurate estimate would track the actual evolution of cumulative capacity instead of assuming a constant global growth rate.

Under the approximate constant growth rate approach, the spill-over benefit per $\mathrm{kW}_{p}$ in- 
stalled in year $t$ from (15) is $s_{t} \equiv c_{t}-d A_{t} / d I_{t}$ or

$$
s_{t}=\left(c_{0}-c_{m}\right) e^{r t}\left(\frac{e^{-(b g+r) t}-e^{-(b g+r) T}}{1+r /(b g)}+e^{-b(g-m) T} \frac{e^{-(b m+r) T}-e^{-(b m+r) N}}{1+r /(b m)}\right) .
$$

With the base assumptions that $c_{0}-c_{m}=\$ 788$, date $T=2028, b g=8.96 \%, N=2035, r=3 \%$, $m=1.75 \%$ and $t$ includes the five years from 2010 (accounting for over $80 \%$ of cumulative capacity), we can calculate the spill-over value each year and, given the cumulative capacity installed in each country shown in Table 2, the total spill-over by country is given in Table 3 (calculated from the spill-over per $\mathrm{kW}_{p}$ in Table 2 and the annual increments to capacity).

Table 2: Installed capacity (GWp) and spillover $(\$ / \mathrm{kWp})$ of Solar PV

\begin{tabular}{|c|c|c|c|c|c|c|c|}
\hline Country & 2010 & 2011 & 2012 & 2013 & 2014 & 2015 & shares \\
\hline China & 0.8 & 3.3 & 6.8 & 19.7 & 28.2 & 43.5 & $19 \%$ \\
\hline Germany & 17.4 & 24.9 & 32.5 & 35.8 & 38.2 & 39.8 & $17 \%$ \\
\hline Japan & 3.6 & 4.9 & 6.6 & 13.6 & 23.3 & 34.2 & $15 \%$ \\
\hline USA & 2.5 & 4.4 & 7.3 & 12.1 & 18.3 & 25.6 & $11 \%$ \\
\hline Italy & 3.5 & 12.8 & 16.5 & 18.1 & 18.5 & 18.9 & $8 \%$ \\
\hline UK & 0.1 & 0.9 & 1.9 & 3.4 & 5.1 & 8.9 & $4 \%$ \\
\hline France & 1.2 & 3 & 4.1 & 4.7 & 5.7 & 6.6 & $3 \%$ \\
\hline subtotal & 29.1 & 54.1 & 75.6 & 107.3 & 137.2 & 177.5 & $76 \%$ \\
\hline Global cumulative capacity & 47 & 78 & 110 & 144 & 184 & 234 & $100 \%$ \\
\hline spillover per $\mathrm{kWp}$ & $\$ 822$ & $\$ 740$ & $\$ 664$ & $\$ 595$ & $\$ 531$ & $\$ 472$ & \\
\hline range of spillover $+/-\%$ & $31 \%$ & $28 \%$ & $26 \%$ & $24 \%$ & $21 \%$ & $19 \%$ & \\
\hline
\end{tabular}

Sources: Wikipedia at https://en.wikipedia.org/wiki/Growth_of_photovoltaics. Detailed notes on sources are provided there. Global figures 2012-15 are taken from ITRPV (2016) and for 2010-2011 extrapolated backwards from (incomplete) country totals.

The range of values of the spillover is the range shown from Table 1 exhibited by $B_{0} / c_{0}$, so the cumulative contribution that these countries have made to global learning benefits ranges from \$83-138 billion (without attributing previous contributions and excluding interest - including interest at $r=3 \%$ would increase the cumulative contribution by $\$ 9$ billion).

\subsection{Funding a global Apollo Programme}

The spill-overs calculated in Table 3 are substantial and unequally divided, with the top three countries contributing over half the global contribution. It is interesting to ask how this total sum might have been made available for subsidy support globally under some international agreement 
Table 3: Spillover value of Solar PV by country, year, and cumulative value, 2010-2015 \$millions

\begin{tabular}{|l|llllll|l|l|}
\hline Country & 2010 & 2011 & 2012 & 2013 & 2014 & 2015 & cumulative & share \\
\hline Germany & $\$ 14,276$ & $\$ 5,536$ & $\$ 5,049$ & $\$ 1,964$ & $\$ 1,292$ & $\$ 737$ & $\$ 28,855$ & $21 \%$ \\
China & $\$ 657$ & $\$ 1,849$ & $\$ 2,324$ & $\$ 7,681$ & $\$ 4,499$ & $\$ 7,234$ & $\$ 24,245$ & $18 \%$ \\
Japan & $\$ 2,973$ & $\$ 958$ & $\$ 1,141$ & $\$ 4,142$ & $\$ 5,148$ & $\$ 5,120$ & $\$ 19,482$ & $14 \%$ \\
USA & $\$ 2,078$ & $\$ 1,372$ & $\$ 1,918$ & $\$ 2,858$ & $\$ 3,291$ & $\$ 3,454$ & $\$ 14,970$ & $11 \%$ \\
Italy & $\$ 2,878$ & $\$ 6,883$ & $\$ 2,420$ & $\$ 963$ & $\$ 205$ & $\$ 219$ & $\$ 13,568$ & $10 \%$ \\
UK & $\$ 63$ & $\$ 612$ & $\$ 662$ & $\$ 878$ & $\$ 916$ & $\$ 1,799$ & $\$ 4,930$ & $4 \%$ \\
France & $\$ 989$ & $\$ 1,309$ & $\$ 741$ & $\$ 382$ & $\$ 492$ & $\$ 438$ & $\$ 4,352$ & $3 \%$ \\
\hline subtotal & $\$ 23,915$ & $\$ 18,519$ & $\$ 14,255$ & $\$ 18,869$ & $\$ 15,842$ & $\$ 19,001$ & $\$ 110,402$ & $80 \%$ \\
\hline range $+/-$ & $\$ 7,323$ & $\$ 5,266$ & $\$ 3,727$ & $\$ 4,480$ & $\$ 3,360$ & $\$ 3,522$ & $\$ 27,678$ & \\
\hline
\end{tabular}

along the lines of the Global Apollo Project. Table 4 shows cumulative emissions for countries accounting for $80 \%$ of $\mathrm{CO}_{2}$ emissions since 1950, and their share in the global total over that period.

If, plausibly, countries were asked to contribute on the basis of their past contributions to the stock of $\mathrm{CO}_{2}$, then the US might be asked to contribute $25 \%$ whereas of the subset of countries in Table 3, it contributed $11 \%$ of the global spill-over benefits (the table accounts for $80 \%$ of cumulative investment). China over-contributes (18\% compared to a $14 \% \mathrm{CO}_{2}$ share) as does Germany (21\% compared to $5 \%$ ) and Italy (10\% compared to $2 \%$ ). The other countries contribute roughly twice as much as their share in global emissions.

A proper global programme would collect funds according to some criterion such as cumulative contributions to the current $\mathrm{CO}_{2}$ stock (perhaps progressive with GDP/head and cumulative emissions per head as part of the formula) and allocate them efficiently. That would be achieved by an annual auction for the least subsidy needed to deliver the annual target, payable per MWh delivered up to some total per $\mathrm{MW}_{p}$ installed (e.g. 20,000MWh/MW , equivalent to 20,000 equivalent full operating hours, $\sum h_{t}$ ) in addition to the wholesale price. That would encourage delivery (i.e. proper installation, connection and maintenance) and allocation to places of high insolation or wind and high avoidable fossil costs. An additional requirement might be an explicit carbon tax or equivalent subsidy to zero-carbon generation.

The decision on the annual amount to auction will need to balance the supply of suitable sites with the manufacturing capacity of the PV industry, and would ideally provide credible commitments for sufficiently far into the future to justify building new PV manufacturing capacity. As PV prices fall, the amount of subsidy required will fall below the future value of the spill-overs, although as better sites are used up, the time taken to earn back the installation costs 
Table 4: Emissions of $\mathrm{CO}_{2}$ by country and share of total emissions from 1950-2013

\begin{tabular}{|l|rrr|}
\hline country & cum $\mathrm{CO}_{2}$, m tonnes & share & cum \\
$1950-2013$ & & share \\
\hline United States & 280,249 & $25 \%$ & $25 \%$ \\
China & 156,643 & $14 \%$ & $39 \%$ \\
Russian Federation & 97,243 & $9 \%$ & $47 \%$ \\
Germany & 56,844 & $5 \%$ & $52 \%$ \\
United Kingdom & 35,789 & $3 \%$ & $55 \%$ \\
Japan & 51,470 & $5 \%$ & $60 \%$ \\
India & 35,049 & $3 \%$ & $63 \%$ \\
France & 22,941 & $2 \%$ & $65 \%$ \\
Canada & 24,185 & $2 \%$ & $67 \%$ \\
Ukraine & 25,591 & $2 \%$ & $70 \%$ \\
Poland & 19,312 & $2 \%$ & $71 \%$ \\
Italy & 19,884 & $2 \%$ & $73 \%$ \\
Mexico & 14,334 & $1 \%$ & $74 \%$ \\
South Africa & 14,099 & $1 \%$ & $76 \%$ \\
Australia & 13,968 & $1 \%$ & $77 \%$ \\
Korea, Rep. (South) & 13,557 & $1 \%$ & $78 \%$ \\
Iran & 11,856 & $1 \%$ & $79 \%$ \\
Spain & 11,424 & $1 \%$ & $80 \%$ \\
\hline
\end{tabular}

Source: CAIT Climate Data Explorer. 2017. Washington, DC:

World Resources Institute, at: http://cait.wri.org

will rise and tend to offset the fall in installation costs.

\section{Conclusions and Policy Implications}

The models demonstrate how to judge whether a given rate of expansion of PV or wind is justified, given assumptions about the future prices of fossil fuel and carbon displaced, as well as, critically, the learning rate and discount rate, and on the asumption that high resource areas are exploited in the most cost-effective sequence. The method here has been applied to constant growth cases as they allow closed form solutions and hence simple and transparent sensitivity analysis, at the cost of understating the benefits of an optimal trajectory. The approach can be 
readily extended to any projected trajectory using the relevant formulae for each period's cost of new investment and its capacity factor, and spreadsheets to evaluate the annual values.

The results suggest that subsidizing solar PV appears justified, and the justified subsidy rates are substantial - in $2015 \$ 470+/-\$ 90 / \mathrm{kW}_{p}$. If this were allocated as a supplement per MWh for the first 20,000 $\mathrm{MWh} / \mathrm{MW}_{p}$, the amount would be $\$ 23.5 / \mathrm{MWh}$, to which should also be added the shortfall in the $\mathrm{CO}_{2}$ price times the $\mathrm{CO}_{2}$ intensity of displaced MWh. For example, if the shortfall were $\$ 15 /$ tonne $\mathrm{CO}_{2}$ and the generation displaced were gas-fired, an additional $\$ 6.5 /$ MWh could be justified, to give a total maximum of $\$ 30 / \mathrm{MWh}(£ 23 / \mathrm{MWh}$ at $\$ 1.3=£ 1)$. With forward summer 2018 baseload prices in GB around $£ 47 /$ MWh (Dec 2017) ${ }^{25}$ and the 2015 auction for solar PV clearing at $£ 79 /$ MWh the implied subsidy was about $£ 32(\$ 42) / \mathrm{MWh}$, somewhat higher than the level justified for a much sunnier country than the UK.

The story for on-shore wind is less promising - whether continued support is justified appears somewhat marginal, although if it were justified the subsidy rates might be $14-22 \%$ (but could be lower). On the assumption (not tested as data are not very reliable) that CCS is justified (and it is difficult to see how we can meet our carbon targets without putting a lot of carbon back underground) Appendix D suggests that capacity subsidies of 14-20\% might be justified, but given the limited evidence on learning rates these are more speculative.

Given a more fully reasoned model of how learning disseminates and the role of induced (or planned) R\&D, it might be possible to compute the optimal trajectory, which would almost certainly start with higher rates of investment, falling over time as the costs of subsidizing an ever larger investment rise while the future cost reductions decline. The resulting justified subsidy rates would differ, perhaps not substantially, from those estimated here. In this simplified model, the main conclusion is that accelerating the current rate of investment appears socially attractive under a wide range of assumptions for PV, less so for on-shore wind (which, fortunately, is approaching viability without subsidy, given a sensible carbon price). The case for supporting Mission Innovation is therefore compelling.

\section{References}

Andor, M. and A. Voss, 2016. Optimal renewable-energy promotion: Capacity subsidies vs. generation subsidies. Resource and Energy Economics, 45, 144-158

Andresen, T. M., 2012. Including Learning in Cost Analyses of Renewable Energy, MPhil thesis, Dept. Economics University of Oslo, at https://www.duo.uio.no/handle/10852/17111

Arrow, K., 1962. The Economic Implications of Learning-by-Doing, Rev. Econ. Stud., 29(3): 155-173.

\footnotetext{
${ }^{25}$ This includes both the Dec 2017 ETS price of $£ 6 / \mathrm{tCO}_{2}$ and the GB carbon support price (effectively a tax) of $£ 18 / \mathrm{tCO}_{2}$, making a total of $£ 24(\$ 30) / \mathrm{tCO}_{2}$.
} 
Bardhan, P.K., 1971. On optimum subsidy to a learning industry: an aspect of the theory of infant-industry protection. Int. Econ. Rev. 12 (1), 54-70.

Bass, R.J. W. Malalasekera, P. Willmot and H.K. Versteeg, 2011. The impact of variable demand upon the performance of a combined cycle gas turbine (CCGT) power plant. Energy, 1956-1965.

Van Benthem, A., K. Gillingham, and J. Sweeney, 2008. Learning-by-doing and the California Solar Initiative. The Energy Journal, 29(3), 131-151.

Bollinger, B. K. and Gillingham, K., 2014. Learning-by-Doing in Solar Photovoltaic Installations. Available at SSRN: https://ssrn.com/abstract=2342406orhttp://dx.doi.org/10.2139/ssrn. 2342406

Bollinger, M., J. Seel, and M. Wu, 2016. Maximizing MWh: A Statistical Analysis of the Performance of Utility-Scale Photovoltaic Projects in the United States, pre-print of an article submitted to Progress in Photovoltaics: Research and Applications, available at https: //emp.lbl.gov/publications/maximizing-mwh-statistical-analysis

Denholm, P. \& R. M. Margolis, 2007. Evaluating the limits of solar photovoltaics (PV) in electric power systems utilizing energy storage and other enabling technologies. Energy Policy, 35(9), 4424-4433. https://doi.org/10.1016/j.enpol.2007.03.004

Dasgupta, P. and J. Stiglitz, 1988. Learning-by-Doing, Market Structure and Industrial and Trade Policies, Oxford Economic Papers, 40(2), pp. 246-268.

Dolphin, G., M. Pollitt and D. Newbery, 2016. The Political Economy of Carbon Pricing: a Panel Analysis. EPRG WP 1627 at https://www.eprg.group.cam.ac.uk/wp-content/uploads/ 2016/11/1627-Text.pdf

EC, 2009. Accompanying document to the SET-Plan - Impact Assessment. European Commission SEC(2009) 1297.

EIA, 2016. International Energy Outlook 2016, at http://www.eia.gov/outlooks/ieo/electricity. cfm

EPRI, 2016. Budgeting for Solar PV Plant Operations $\&$ Maintenance: Practices and Pricing, at http://prod.sandia.gov/techlib/access-control.cgi/2016/160649r.pdf

Fraunhofer, 2016. Photovoltaics Report, Fraunhofer Institute for Solar Energy Systems at http://www.ise.fraunhofer.de

Gambhir, A., R. Gross and R Green, 2014. The impact of policy on technology innovation and cost reduction: a case study on crystalline silicon solar PV modules. Imperial College WP, at https://www.imperial.ac.uk/media/imperial-college/grantham-institute/public/ publications/working-papers/The-impact-of-policy-on-technology-innovation-and-cost-reduction-WP. pdf 
Ghemawat, P. and A. M. Spence, 1985. Learning Curve Spillovers and Market Performance. QJE, 100, (Supplement), 839-852.

Grubb, M., J. Köhler and D. Anderson, 2002. Induced technical change in energy and environmental modeling: analytic approaches and policy implications, Annual Review of Energy and the Environment, 27: 271-308 https://doi.org/10.1146/annurev.energy.27.122001.083408

Hirth, L., 2018. What cause the drop in European electricity prices? A factor decomposition analysis. The Energy Journal, 19(1), 132-157.

HoC, 2016. The Carbon Price Floor, Briefing Paper CBP05927, House of Commons

Hoste, G.R.G, M.J. Dvorak \& M. Z. Jacobson, 2011. Matching Hourly and Peak Demand by Combining Different Renewable Energy Sources: A case study for California in 2020, Stanford University Department of Civil and Environmental Engineering, at http://www.etopia.be/IMG/ pdf/HosteFinalDraft.pdf

IEA, 2017. Snapshot of Global Photovoltaic Markets 201\%. International Energy Agency. 19 April 2017, at http://www.iea-pvps.org/retrieved17July2017.

IRENA, 2016, The Power to Change: Cost reduction potentials for solar and wind power technologies, at http://www.irena.org/DocumentDownloads/Publications/IRENA_Power_to_Change_ 2016.pdf

ITRPV, 2016. International Technology Roadmap for Photovoltaic Results, Seventh Edition 2016, at http://www.itrpv.net/Reports/Downloads/2016/

Jamasb, T., 2007. Technical change theory and learning curves: Patterns of progress in electricity generation technologies. The Energy Journal, 28, 51-72.

Jordan, D.C. and S.R. Kurz, 2013. Photovoltaic Degradation Rates - An Analytical Review, Progress in Photovoltaics: Research and Applications, 21(1), 12-29.

Kalkuhl, M., Edenhofer, O., Lessmann, K., 2012. Learning or lock-in: optimal technology policies to support mitigation. Resource and Energy Economics 34, 1-23.

King, D., J. Browne, R. Layard, G. O'Donnell, M. Rees, N. Stern \& A. Turner, 2015. A global Apollo programme to combat climate change, LSE, at cep.lse.ac.uk/pubs/download/special/

Global_Apollo_Programme_Report.pdf

Lehmann, P.,2013. Supplementing an emissions tax by a feed-in tariff for renewable electricity to address learning spillovers. Energy Policy, 61, 635-41.

Lieberman, M.B., 1987. The Learning Curve, Diffusion, and Competitive Strategy, Strategic Management Journal, 8(5), 441-452.

Mazzola, J.B. and K.F. McCardle, 1997. The Stochastic Learning Curve: Optimal Production in the Presence of Learning-Curve Uncertainty, Operations Research, 45(3), 440-450.

McMillan, C.J., 1984. The Japanese Industrial System. Walter de Gruyter, Berlin 
Neuhoff, K., 2008. Learning by Doing with Constrained Growth Rates: An Application to Energy Technology Policy. 2008 Special Issue: The Future of Electricity: Papers in Honor of David Newbery, The Energy Journal, 165-182.

Newbery, D.M., 2016. A simple introduction to the economics of storage: shifting demand and supply over time and space, EPRG WP 1626, at http://www.eprg.group.cam.ac.uk/ wp-content/uploads/2016/10/1626-Text.pdf

Newbery, D.M. 2017. How to judge whether supporting solar PV is justified. EPRG Working Paper 1706 at https://www.eprg.group.cam.ac.uk/wp-content/uploads/2017/03/1706-Text_ upd.pdf

Newbery, D.M. (2018) "What future(s) for liberalized electricity markets: efficient, equitable or innovative?" The Energy Journal, 39(1), 1-27. Doi:10.5547/01956574.39.1.dnew

Nordhaus, W.D., 2014. The Perils of the Learning Model for Modeling Endogenous Technological Change. The Energy Journal, 35(1): 1- 13.

NREL, 2016. U.S. Solar Photovoltaic System Cost Benchmark: Q1 2016, by R. Fu, D. Chung, T. Lowder, D. Feldman, K. Ardani, and R. Margolis, National Renewable Energy Laboratory, at https://www.nrel.gov/docs/fy16osti/66532.pdf

Papineau, M, 2006. An economic perspective on experience curves and dynamic economies in renewable energy technologies, Energy Policy 34(4), 422-32 https://doi.org/10.1016/j.enpol. 2004.06.008

Rasmussen, T. N., 2001. $\mathrm{CO}_{2}$ abatement policy with learning-by-doing in renewable energy. Resource and Energy Economics, 23 (4), 297-325 at https://www.sciencedirect.com/science/ article/pii/S0928765501000410

Reichenbach, J., Requate, T., 2012. Subsidies for renewable energies in the presence of learning effects and market power. Resour. Energy Econ. 34 (2), 236-254.

Rosendahl, K. E., 2004. Cost-effective environment policy: implications of induced technological change, Journal of Environmental Economics and Management, 48 (3), 1099-1121. https://www.sciencedirect.com/science/article/pii/S0095069604000142

Rubin, E.S., 2014. Reducing the cost of CCS through "Learning by doing", presentation to Clearwater Coal Conference, June 2, at https://www.cmu.edu/epp/iecm/rubin/PDF\%20files/ 2014/Reducing\%20the\%20Cost\%20of\%20CCS\%20through\%20Learning\%20by\%20Doing.pdf

Rubin, E.S., I. M.L. Azevedo, P. Jaramilloa, \& S. Yeh, 2015a. A review of learning rates for electricity supply technologies. Energy Policy 86, 198-218.

Rubin, E.S., J.E. Davison, \& H.J. Herzog, 2015. The cost of $\mathrm{CO}_{2}$ capture and storage, International Journal of Greenhouse Gas Control, 40, 378-400, https://doi.org/10.1016/j.ijggc. 2015.05.018 
Sensfuß, F. M. Ragwitz, M. Genoese, 2008. The merit-order effect: A detailed analysis of the price effect of renewable electricity generation on spot market prices in Germany, Energy Policy, 36,(8), 3086-3094, https://doi.org/10.1016/j.enpol.2008.03.035

Spence, M. A., 1981. The Learning Curve and Competition, The Bell Journal of Economics, $12(1), 49-70$.

Succar, P., 1978. The Need for Industrial Policy in LDC's - A Re-Statement of the Infant Industry Argument, International Economic Review, Vol. 28, No. 2 (Jun., 1987), pp. 521-534, at http://www.jstor.org/stable/2526741

US EPA, 2016. Technical Update of the Social Cost of Carbon for Regulatory Impact Analysis Under Executive Order 12866, at https://www.epa.gov/sites/production/files/2016-12/ documents/sc_co2_tsd_august_2016.pdf

Wikipedia, 2016. Swanson's Law (derived from ITRPV, 2016) at https://en.wikipedia.org/ wiki/File:Swansons-law.svg(accessed6/3/17)

World Energy Council, 2017. World Energy Resources Wind | 2016, at https://www. worldenergy.org/wp-content/uploads/2017/03/WEResources_Wind_2016.pdf

\section{A Calibrating the model for solar PV}

\section{A.1 Unit costs}

ITRPV (2016) gives the 2015 global average module price as US $\$ 0.58 / \mathrm{W}_{p}$, with an installed base at end-2015 of $234 \mathrm{GW}_{p} \cdot{ }^{26}$ Module for large ( $>100 \mathrm{~kW}$ systems) in the US and Europe represent only $55 \%$ of the total system cost (excluding "soft costs"), making the assumed system price US\$ $1,090 / \mathrm{kW}_{p}$. NREL (2016) gives US cost estimates for the total installed cost of utility-scale installations for Q1, 2016, including all the installation, permitting and grid connection costs and (expensive) US labour costs, as US\$ $1.14 / \mathrm{W}_{p}$ for a fixed-tilt $100 \mathrm{MW}$ array in Oklahoma (the cheapest state, with non-unionised labour). The cost of a one-axis tracking unit there would be US\$1.19/ $\mathrm{W}_{p}$, and tracking is cost-effective given the resulting higher capacity factor. Installation costs should be lower in countries with lower labour costs as the US labour element is US\$ $0.16 / \mathrm{W}_{p}$. The average module price (rather than the US figure) with half the US labour cost for a tracking system is US $\$ 1,050 / \mathrm{kW}_{p}$ for the start date of 2015 .

\footnotetext{
${ }^{26}$ Prices may be above or below costs. The US data discussed below are built up from cost components and will be higher than costs in China. The average 2015 cost relates to a level of cumulative production lower than the end of the year value, so future cost reductions are slightly under-estimated.
} 


\section{A.2 Calibrating penetration}

The point at which solar PV penetration reaches its limit at date $T$ is determined by the global pattern of solar insolation, and the number of equivalent operating hours below which PV is not competitive with other low carbon generation, $h_{T}$. If $h_{0}=2,500 \mathrm{hrs}$ (exceeded in favoured locations, see http://geosun.co.za/services-products/prospect-evaluate/solar-maps-and-layers/), and $h_{T}=900 \mathrm{hrs}$ (roughly North Denmark and northern Canada) then $h_{T} / h_{0}=e^{-\zeta g T}$ so $\zeta g T=1.022$. If it takes 13 years to move from 2, $500 \mathrm{hrs}$ to $900 \mathrm{hrs}$ when PV investment grows at $g=25 \%$, then $K_{T} / K_{0}=25.8$ and $\zeta=0.314$. Saturation penetration would be $Y_{K_{T}} / Y_{0}=13.1$. PV generation in 2016 is estimated at $1.8 \%$ of global generation, with Honduras producing $12.5 \%$ of its demand from PV (IEA, 2017). Our reference data are mostly from 2015, when the share was closer to $1.5 \%$, so, allowing for total electricity growth of $2.25 \%$ p.a. until 2020 and thereafter $1.75 \%,{ }^{27}$ global saturation would be $15 \%$, which seems plausible, given current highest levels of penetration. Saturation is defined by $h_{T}$ (i.e. by $K_{T}$ ) and if $\zeta$ is a physical parameter, but $g$ and hence $T$ varies so that if $g=20 \%$, then $T=16.3 \mathrm{yrs}$, with final penetration at $14.5 \%$. If $g=15 \%, T=21.7$ yrs and the higher total generation then would lower PV penetration to $13 \%$.

\section{B Integration formulae}

Many of the derivations involve solving $\int_{t}^{M} e^{\alpha t} d t=\left(e^{\alpha M}-e^{\alpha t}\right) / \alpha \equiv \Psi(\alpha, t, M)$, where $\Psi$ is an operator (and a useful spreadsheet function). The formula for the PDV of costs at date $t, C_{t 0}$, on the investment trajectory on which $c_{m}=0$, (in eq. (1)) and (9) is, after substituting for $I_{t}=d K_{t} / d t$ from $(3)$,

$$
\begin{aligned}
\frac{C_{t 0}}{K_{0}} & =c_{0} e^{r t}\left(\int_{t}^{M i n(T, N)} g e^{((1-b) g-r) u} d u+m e^{(1-b)(g-m) T / N} \int_{M i n(T, N)}^{N} e^{((1-b) m-r) u} d u\right) \\
& \left.\left.=c_{0} e^{r t}(g \Psi((1-b) g-r), t, T / N)+m e^{((1-b)(g-m) T} \Psi((1-b) m-r), T / N, N\right)\right),
\end{aligned}
$$

where $T / N$ is short for $\operatorname{Min}(T, N)$. In the more plausible case where $\phi>0$ as in (2),

$$
\begin{aligned}
& \frac{C_{t}}{K_{0}}=(1-\phi) \frac{C_{t 0}}{K_{0}}+\phi c_{0} e^{r t}\left(g \int_{t}^{M i n(T, N)} e^{(g-r) u} d u+m e^{(g-m) T / N} \int_{M i n(T, N)}^{N} e^{(m-r) u} d u\right), \\
& \frac{C_{t}}{K_{0}}=(1-\phi) \frac{C_{t 0}}{K_{0}}+\phi c_{0} e^{r t}\left(g\left(\Psi(g-r, t, T / N)+m e^{(g-m) T / N} \Psi(m-r, T / N, N)\right),\right.
\end{aligned}
$$

where $C_{t 0}$ is the PDV to date $t$ of cost when $c_{m}=0=\phi$.

\footnotetext{
${ }^{27}$ https://www.eia.gov/outlooks/ieo/electricity.php
} 


\section{B.1 The pre-saturation benefit}

The pre-saturation benefit attributable to post- $t$ investment is, from (11)

$$
\begin{aligned}
F_{t}= & \frac{h_{0} K_{0} e^{r t}}{1-\zeta}\left(\begin{array}{c}
\int_{t}^{M i n(T, N)} e^{-r u}\left(e^{(1-\zeta) g u}-e^{(1-\zeta) g t}\right)\left(p_{0} e^{-\pi u}+\gamma_{0} e^{i u}\right) d u \\
+\left(e^{g(1-\zeta) T}-e^{(1-\zeta) g t}\right) e^{-m T} \int_{M i n(T, N)}^{N}\left(p_{0} e^{-\pi u}+\gamma_{0} e^{i u}\right) e^{(m-r) u} d u
\end{array}\right), \\
= & \frac{h_{0} K_{0} e^{r t}}{1-\zeta}\left(\begin{array}{c}
p_{0}\left\{\Psi((1-\zeta) g-r-\pi, t, T / N)-e^{(1-\zeta) g t} \Psi(-r-\pi, t, T / N)\right\}+ \\
\gamma_{o}\left\{\Psi((1-\zeta) g+i-r, t, T / N)-e^{(1-\zeta) g t} \Psi(i-r, t, T / N)\right\}+ \\
\left(e^{g(1-\zeta) T}-e^{(1-\zeta) g t}\right) e^{-m T}\left[p_{0} \Psi(m-r-\pi, T / N, N)\right. \\
\left.+\gamma_{0} \Psi(m+i-r, T / N, N)\right]
\end{array}\right) .
\end{aligned}
$$

\section{B.2 The capacity credit for wind}

The capacity credit for wind from (12) is

$$
\begin{aligned}
& \frac{\Pi_{w t}}{K_{0}}=\frac{P h_{0} e^{r t}}{17,520(1-\zeta)}\left(\begin{array}{c}
\int_{t}^{M i n(T, N)}\left(e^{(1-\zeta) g u}-e^{(1-\zeta) g t}\right) e^{-r u} d u+ \\
\left(e^{(1-\zeta) g T / N}-e^{(1-\zeta) g t}\right) e^{-m T / N} \int_{M i n(T, N)}^{N} e^{(m-r) u} d u
\end{array}\right), \\
& \frac{\Pi_{w 0}}{K_{0}}=\frac{P h_{0} e^{r t}}{17,520(1-\zeta)}\left(\begin{array}{c}
\Psi((1-\zeta) g-r, t-T / N)-e^{(1-\zeta) g t}(\Psi(-r, t-T / N) \\
+\left(e^{(1-\zeta) g T / N}-e^{(1-\zeta) g t}\right) e^{-m T / N} \Psi(m-r, T / N-N)
\end{array}\right) .
\end{aligned}
$$

\section{B.3 The evolution of the subsidy}

The evolution of the subsidy can be rearranged from (16) as

$$
\frac{B_{t}}{c_{0}}=(1-\phi) \frac{e^{-b g t}-e^{r t}}{1+r /(b g)}+e^{r t} \frac{B_{0}}{c_{0}}
$$

so the net (relative) cost at date $t$ is

$$
\begin{aligned}
n_{t} & =\frac{B_{t}-c_{t}}{c_{0}}=(1-\phi) \frac{e^{-b g t}-e^{r t}}{1+r /(b g)}+e^{r t} \frac{B_{0}}{c_{0}}-\phi-(1-\phi) e^{-b g t} \\
& =e^{r t}\left(\frac{B_{0}}{c_{0}}-\frac{1-\phi}{1+r /(b g)}\right)-\phi-(1-\phi) \frac{e^{-b g t}}{1+b g / r}
\end{aligned}
$$

where

$$
\begin{aligned}
\frac{B_{0}}{c_{0}} & =(1-\phi)\left(\frac{1-e^{-(b g+r) T}}{1+r /(b g)}+\frac{e^{-(b g+r) T}-e^{-(b m+r) N-b(g-m) T}}{1+r /(b m)}\right) \\
n_{t} & =(1-\phi) e^{r t}\left(\frac{e^{-(b g+r) T}-e^{-(b m+r) N-b(g-m) T}}{1+r /(b m)}-\frac{e^{-(b g+r) T}}{1+r /(b g)}-\frac{e^{-(b g+r) t}}{1+b g / r}\right)-\phi .
\end{aligned}
$$

As $t$ becomes large and negative (going back into the past) this expression will tend to $-\frac{(1-\phi)}{1+b g / r} e^{-b g t}-$ $\phi$ and hence to a negative net cost, but this seems to involve an extremely distant past, after which the net cost remains positive. 


\section{Wind}

Mean learning rates for on-shore wind are given as 12\% (one-factor model) or $9 \%$ (two-factor) in Rubin et al. (2015) and 7\% (investment costs) or 12\% (levelised costs of electricity) by IRENA (2016). Capacity factor data is available from OpenEI's Transparent Cost Database, ${ }^{28}$ which suggests a maximum on-shore CF of $50 \%$ or 4,380 hrs. The average US CF was $34.7 \%$ or just over 3,000 hrs. ${ }^{29}$ The global average cost of on-shore wind in 2015 was $\$ 1,560$ projected to fall to $\$ 1,370$ by 2025 (IRENA, 2016), but increasing hub height increases both the capital cost and also the capacity factor, with the combination lowering levelised costs. Installed capacity at the end of 2016 was $486 \mathrm{GW}$ (of which about 12 GW was off-shore), growing by $12 \%$ in 2016 (GWEC, 2017). World Energy Council (2017) notes that "A technical and economic potential exists to accelerate deployment and reach 1879-2318 GW in 2030" although this includes a large share of off-shore wind.

The wind power penetration in world electric power generation in 2015 was $3.5 \%$ but is over $40 \%$ in Denmark (which exports surplus wind) and is planned to reach nearly $40 \%$ in the island of Ireland by 2020 (with limited export capacity). More relevant, the plan is to develop flexible services to accommodate System Non-Synchronous Penetration (effectively the share of variable renewables) of up to $75 \%$ by 2020 . This might be delivered under conditions of high wind and low demand, suggesting that $40 \%$ average wind share is challenging without strong interconnection with other regions experiencing relatively uncorrelated wind output.

\section{Carbon capture and storage}

The model above applies directly to solar PV, wind, tidal or wave power in that it assumes that resource availability is location specific. Carbon capture and storage (CCS) in contrast is less constrained by location (primarily needing access to underground $\mathrm{CO}_{2}$ storage but pipelines can access distant sites), so that (4) no longer determines saturation and market output. In addition CCS is dispatchable and has a higher capacity credit than its nominal capacity provided it can by-pass the capture plant, temporarily raising its output by about $25-30 \%$. The other major difference is that the installed base is currently tiny - IEA reports that "The 17 operational large-scale projects have a total potential capture rate of over $30 \mathrm{MtCO}_{2}$ per year". ${ }^{30}$ Many of these are industrial plant, but to give some perspective, if 1 tonne $\mathrm{CO}_{2} / \mathrm{MWh}_{e}$ are captured (based on coal-firing), this is only equivalent to $4.5 \mathrm{GW}$ of generation (Rubin et al., 2015b).

\footnotetext{
28 at https://openei.org/apps/TCDB/

${ }^{29}$ see https://www.eia.gov/electricity/monthly/epm_table_grapher.php?t=epmt_6_07_b

${ }^{30}$ https://www.iea.org/etp/tracking2017/carboncaptureandstorage/ accessed 14 Dec 2017.
} 
In contrast China has been commissioning $50+\mathrm{GW}$ of coal plant per year recently, while globally some $900 \mathrm{GW}$ of new coal capacity has been commissioned since 2000 with an additional 400 GW expected by 2040. ${ }^{31}$ Current global installed capacity of coal-fired generatiion is nearly $2,000 \mathrm{GW},{ }^{32}$ generating about $40 \%$ of total electricity or 10,000 TWh. ${ }^{33}$ Clearly the global rate of additions of coal capacity can reach 60-100 GW/yr, so CCS has a potentially large market (at $40 \%$ of projected 2040 generation, some 15,000 TWh, or 3,000-4,000 GW (at the same capacity factor as coal, and allowing for the lower efficiency of CCS). If storage sites can be accessed suitably rapidly and extensively, CCS could sustain a high maximum rate of capacity additions for many years - $100 \mathrm{GW} / \mathrm{yr}$ would only deliver 2,500 GW by 2040 .

Modeling CCS growth is complicated by the lack of much past evidence, and the barriers to mass deployment are far higher than for wind and PV, as CCS units are large and very costly while wind and PV are relatively small and modular. One approach is to assume a very high rate of growth $g$ until date $T$ when $I_{T}$ reaches some plausible limit (80-100 GW/yr) and then assume the same rate of growth of $I_{t}$ as that of demand, $m$. Then

$$
K_{t}=K_{0}+\int_{0}^{M i n(t, T)} I_{0} e^{g u} d u+I_{0} e^{(g-m) \operatorname{Min}(t, T)} \int_{M i n(t, T)}^{M i n(t, N)} e^{m u} d u
$$

Over the period to 2040 all CCS plants should remain operational, thereafter they can be treated as before post- $N$. If $I_{0}=1.25 \mathrm{GW},{ }^{34} \mathrm{~g}=25 \%, K_{0}=I_{0} / g=5 \mathrm{GW}$, and $T=12$ yrs, then $K_{T}=100 \mathrm{GW}$, which is not impossible. With these adjustments, the subsidy formula (16) still applies, although the parameters will differ. There is little data from which to estimate the learning rate. Earlier estimates suggested $\lambda=5 \%$, a somewhat optimistic median value, ${ }^{35}$ for which $b=0.074$. As to the long-run minimum cost, $c_{m}$, Rubin et al., (2015b, p14) cites estimated reductions for the levelised cost of electricity based on the component parts of combustion CCS of $15 \%$ and $20 \%$ for gasification CCS after $100 \mathrm{GW}$ capacity. Taking all these data at face value, the 20-fold increase in $K$ with $b=0.074$ and $c_{T} / c_{0}=0.85$ gives $\phi=25 \%$, the base case value assumed for solar PV, but perhaps implausibly low for a technology many of whose component parts have been extensively deployed in other industries. Taking these numbers at face value ( $T=12 \mathrm{yrs}, N=25 \mathrm{yrs}, r=3 \%$ ) equation (16) gives $=B_{0} / c_{0}=12.7 \%$. If $\lambda=3 \%, \phi=50 \%$

\footnotetext{
${ }^{31}$ IEA World Energy Outlook 2017

${ }^{32}$ https://www.worldcoal.org/installed-coal-generation-capacity-countryregion-1

${ }^{33}$ https://www.bp.com/en/global/corporate/energy-economics/statistical-review-of-worldenergy/electricity.html

${ }^{34}$ Boundary Dam, the first operational plant at scale, has $110 \mathrm{MW}$ from just one retrofitted unit, and there are many stations of above 2 GW size.

${ }^{35}$ Rubin et al. (2015) cite a small number of studies suggesting a projected range of values of $\lambda$ mostly $1-10 \%$. Rubin (2014) gives median values for the more mature technolgies of just over $2 \%$. IGCC+CCS has a median estimated at $5 \%$, oxyfuel at $3 \%$, but they are not based on historical data, only similar technologies or components.
} 
then $B_{0} / c_{0}=5.2 \%$. If $100 \mathrm{GW}$ exhausts all the learning benefits, $N=T=12$, then (16) gives $B_{0} / c_{0}=(1-\phi) b g \Psi(-(b g+r), T)$ and $B_{0} / c_{0}=5.2 \%$ as the second term in the bracket in (16) is tiny. If $\lambda=4 \%, N=T=12$, and $\phi=0 \%$ then $B_{0} / c_{0}=13.7 \%$. Thus the results are relatively insensitive to $N$, but directly sensitive to $1-\phi$. 